
pela Escola de Comunicações e Artes da Universidade de São Paulo (ECA/USP). É diretora da Oboré Projetos Especiais e coordenadora de seu Núcleo de Rádio. Suas atividades podem ser encontradas de forma mais detalhada no site http://www.obore.com

e-mail: analuisa@obore.com

\title{
UNINDO PONTAS SOLTAS
}

Empresa de projetos especiais trabalha com comunicação popular utilizando o rádio para disseminar cultura, educação, saúde e cidadania

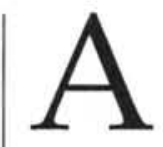

Oboré Projetos Especiais em Comunicações e Artes foi criada em 1978 por um grupo de jornalistas e artistas originários da Escola de Comunicações e Artes da USP. Nasce com a vocação de trabalhar com comunicação popular. Nos primeiros 15 anos, concentra-se na imprensa sindical, fazendo jornais, boletins, revistas, campanhas e consultoria de planejamento de comunicação para sindicatos de trabalhadores urbanos. A partir de 1994, passa a desenvolver projetos de comunicação para trabalhadores rurais, sobretudo com rádio. Constitui um núcleo de criação, produção e distribuição de programas especiais para rádios cidadãs, inventariando o universo das pequenas e médias emissoras do interior do Brasil e resgatando o importante papel que essas redes de rádio têm a desempenhar no trato de questões como educação, saúde, meio ambiente, agricultura, desenvolvi- mento local, direitos (especialmente os das crianças) e música. Dedica-se também à montagem de Agências de Notícias Radiofônicas, ao desenvolvimento de projetos e produtos de educação a distância, planejamento estratégico de mídias e concepção, implantação e gerenciamento de redes temáticas de comunicação. A importância dessas redes já foi reconhecida por quatro importantes prêmios: Prêmio Vladimir Herzog de Anistia e Direitos Humanos (97); Grande Prêmio Ayrton Senna de Jornalismo (99); Prêmio Luiz Beltrão de Ciências da Comunicação (2000) e Medalha e Menção Honrosa Destaques da Saúde concedida pelo ConseIho do Centenário da OPAS - Organização Pan-Americana da Saúde (2002).

Sua vocação de escola materializa-se na realização de cursos para estudantes de jornalismo (Projeto Repórter do Futuro), cursos de capacitação para radiocomunicadores e comunicadores populares, 
além de oficinas temáticas de comunicação para profissionais de diversas áreas.

Desde 1999 desenvolve uma parceria com a Faculdade de Saúde Pública da Universidade de São Paulo (FSP) e seu Centro de Educação Permanente (CEP) para a realização dos Cursos de Informação sobre Saúde Pública para Radiocomunicadores. Com o apoio do Ministério da Saúde, através da Secretaria de Políticas de Saúde, tem por objetivo fazer com que a Universidade se envolva na qualificação desses profissionais e que esses, por sua vez, se envolvam na divulgação da prevenção dos grandes problemas de saúde da população.

Foi chamada a participar da equipe de capacitadores do projeto Educom.rádio, coordenado pela Secretaria Municipal da Educação de São Paulo e pelo Núcleo de Comunicação e Educação da Escola de Comunicações e Artes da Universidade de São Paulo, planejado para desenvolver-se de 2001 até 2004, respondendo pelos blocos de Políticas de comunicação e participação popular e pelo eixo temático Saúde e comunicação.

\section{COSTURA NECESSÁRIA}

Faço parte de uma grande e variada equipe de jornalistas, radialistas, músicos, webmasters, engenheiros, especialistas em informática e alguns apaixonados pelas chamadas novas tecnologias que têm se dedicado a pensar e a manter, cada um do seu jeito, um espaço na Oboré dirigido ao rádio e seus diversos subprodutos. Este núcleo começa a dar sinais de vida em fins de 1992 mas, efetivamente, instala-se apenas em 95, com o desdobramento da en- tão Oboré Editorial em Oboré Projetos Especiais em Comunicações e Artes.

Neste grupo heterogêneo, minha formação em Jornalismo - com passagens pontuais em assessoria de imprensa e em coordenações de departamentos, equipes e publicações - fez com que, naturalmente, minha contribuição começasse a ser sentida no aspecto administrativo do Núcleo, ou seja, na gestão e acompanhamento dos seus produtos e processos. Era uma costura necessária, dadas as diferenças de campo desses profissionais que, nos raros momentos em que estavam juntos - era e ainda é uma dificuldade organizar reuniões com todos os integrantes - os encontros transformavam-se em desencontros: uma babel, onde faltava... comunicação!

Aos poucos, fomos nos

organizando melhor. $\mathrm{Na}$ realidade, os sonhos, os projetos, e principalmente o trabalho a fazer, encarregavam-se de nos alinhar, de nos alinhavar.

Ainda persiste a dificuldade em marcar reuniões gerais entre os vários subsistemas do Núcleo. Reunir, por exemplo, os engenheiros que atuam na produção dos bancos de dados georreferenciados ${ }^{1} \mathrm{e}$ os editores dos programas é quase uma tarefa de outro planeta. Aparentemente, nada têm a planejar juntos. Essencialmente, tudo: a localização das emissoras e respectivas áreas de alcance de suas antenas podem fornecer importantes dados sobre

1. Emprego de superposição de informações diferentes num mesmo mapa. 
a população atingida, índices sociais, epidemias, que influenciam diretamente as pautas dos programas. Reunir o pessoal do tráfego/expedição e o pessoal da edição já é mais simples, mas não fácil. Interessante que, quando chega perto de um feriado ou mesmo no final de ano, as equipes se auto-convocam para o planejamento, dando provas de que reuniões como essa são necessárias e fundamentais para organizar o pleno desenrolar dos processos e produtos.

\section{MÃOS E MENTES EM AÇÃO}

Mas, devo confessar que essa equipe, à qual venho me referindo, nem é tão grande assim. Umas trinta e cinco, quarenta pessoas, se contarmos todas as mãos e mentes que entram em ação em alguma das etapas compreendidas entre a criação e a distribuição dos programas de rádio e o gerenciamento das atuais três redes temáticas em curso na Oboré. Talvez a grande dificuldade em compreender a importância dos encontros entre as equipes seja a falta de noção real sobre a proposta, digamos, política, do Núcleo. Nessas horas me vem à lembrança aquela estória dos três trabalhadores da construção civil que estavam erguendo uma parede. Perguntados sobre o que estavam fazendo, disse o primeiro: estou erguendo uma parede. Disse o segundo: estou fazendo uma casa. E o terceiro: estou ajudando a construir uma cidade.

Hoje, temos mais clareza do papel real de um Núcleo que cria, produz e distribui programas especiais de rádio para emissoras cidadãs - comerciais e comunitárias - reunidas em redes temáticas de parceria e cooperação. Primeiro: o Núcleo existe para servir às emissoras nas suas demandas reais de programação de qualidade e subsistência financeira. Mesmo não tendo a parceria nenhuma finalidade ou relação financeira: a emissora sempre recebe programas de graça e a sua veiculação também não prevê remuneração alguma. Há, sim, espaço nos programas para conquista de publicidade local. Ou seja, cada um dá o que tem e isso não tem a ver com contrapartida homogênea. É, mesmo, uma relação desigual, porém justa. Segundo: consideramos o rádio um veículo popular, por natureza e definição. Chega com mais facilidade a todas as pessoas, principalmente às das camadas mais pobres da população brasileira, que se informa pelo rádio - e muitas vezes só pelo rádio - e elege uma emissora e só uma emissora, e dentro dela um comunicador que se transforma em amigo e até confidente. Terceiro: queremos levar esses radialistas, grandes formadores de opinião junto ao público, os quais podem ajudar a elevar o padrão do rádio enquanto potencializador de políticas públicas como saúde, educação, meio-ambiente, desenvolvimento local, agricultura, música e cultura, por exemplo. Eles estão nos quatro cantos do Brasil, atuando nas pequenas e médias emissoras do interior do País e fazendo a cabeça de milhões e milhões de pessoas por dia. Quarto: queremos alterar. É preciso qualificar as pessoas para que assumam grandes papéis em grandes projetos que alterem o mundo. E elegemos o rádio como protagonista e aliado nesta mudança.

$\mathrm{O}$ exercício permanente, individual e coletivo, da reflexão sobre o trabalho feito é o de realizar, assim como entender e praticar a comunicação popular como uma 
política pública que, se bem feita, pode transformar um bando em um povo. É o diferencial entre uma empresa prestadora de serviços que produz e distribui material radiofônico e uma empresa que presta serviços produzindo e distribuindo material radiofônico em regime de parceria e cooperação. Tal diferença também é marcada, sim, na sua forma de gestão. E na compreensão de que reciclagens e capacitações são atividades permanentes para a vida dos profissionais - e também amadores - quaisquer que sejam seu campo de atuação.

\section{GESTÃO DA COMUNICAÇÃO}

E foi pensando em todas essas coisas, e em muitas outras, que planejei, em 2000, minha especialização em Gestão de Processos Comunicacionais, iluminando no plano de estudo as redes temáticas de rádio e discutindo a parceria e a cooperação como ferramentas de gestão. $\mathrm{O}$ plano de intervenção apresentou um Modelo de Gestão $o^{2}$ (entendido como um caminho que se vai construindo no gerúndio, sempre) com cinco etapas básicas de construção de redes de parceria: criação, montagem, operacionalização, manutenção e, principalmente, avaliação de resultados. O Gestor deveria atuar no momento gerencial da empresa e na mediação entre as diversas equipes e etapas do processo, valorizando a atividade intelectual e a prática reflexiva em cada ponto do sistema. O desafio, portanto, começa agora. Há o desenho do que será e este caminho agora começa a ser escrito com mais ferramentas, com mais idéias, com mais pessoas. Mas há uma di- reção, há critérios e há motivos. E tudo isso, junto, facilita prosseguir.

Quatro grandes iniciativas de caráter nacional visam a integrar emissoras de rádio na divulgação de temas públicos e sociais através de parcerias. A pioneira é a Rede de Rádios da Pastoral da Criança, organismo social da CNBB - Conferência Nacional dos Bispos do Brasil que, através de convênio firmado em 1991 com o Ministério da Saúde, cria, entre outras importantes ações ligadas à saúde materna e infantil, um programa radiofônico semanal chamado Viva a Vida. Já são 1.343 emissoras, em todo o Brasil, que integram esse esforço coletivo de combater a desnutrição infantil e reduzir os índices de mortalidade de milhares de crianças que são ceifadas antes de completar o seu primeiro ano de vida. Este importante trabalho de comunicação pode ser conhecido no site http:// www.rebidia.org.br.

A Oboré Projetos Especiais responde pela configuração das outras três redes, com papel ativo tanto na concepção, montagem e gestão, como na produção do material que abastece periodicamente o trabalho de cerca de 900 emissoras comerciais e comunitárias de todo o Brasil, em sistema de parceria e cooperação.

A Rede de Rádios do Movimento Sindical de Trabalhadores Rurais nasce em 1993 e abastece atualmente 276 emissoras com o programa semanal $A$ Voz da Contag. É mantida pela Confederação Nacional dos Trabalhadores na Agricultura e chega ao seu $10^{\circ}$ ano como uma experiência ímpar de comunicação sindical no Brasil e América Latina. 
A Rede de Comunicadores pela Saúde foi criada em 1999 e é mantida pela Oboré, com patrocínios privados (como Sintofarma, Tramontina e mais recentemente, Aché). Formada atualmente por 602 emissoras comerciais e comunitárias que transmitem o programa semanal Plantão Saúde em dias e horários prédeterminados, a rede alcança 4.995 municípios brasileiros e uma população estimada em 60 milhões de pessoas.

\section{Rede de Comunicadores pela Saúde}

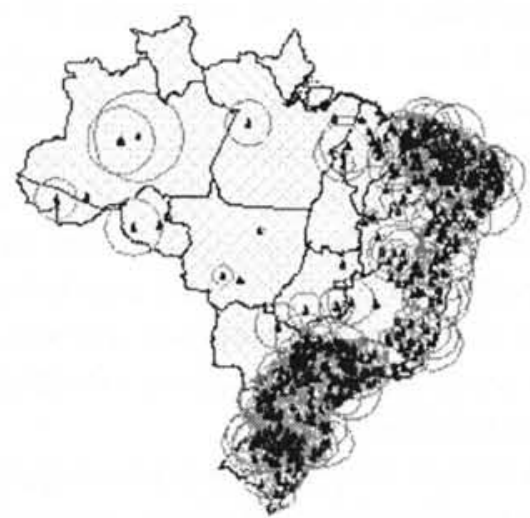

Mapa com as áreas de alcance das 602 emissoras integrantes da Rede de Comunicadores Saúde. Data de lançamento da Rede: julho de 1999. Situaçăo de 30 de janeiro de 2003.

A mais recente experiência nessa área é a Rede de Rádios Escola Campeã, criada em 2002 para abastecer emissoras de 49 municípios de 24 estados brasileiros parceiros do Instituto Ayrton Senna e da Fundação Banco do Brasil no Programa Escola Campeã, que visa contribuir para a melhoria da qualidade da educação nas escolas da rede pública, garantindo, com isso, o sucesso dos alunos. Sua formação atual é de 65 emissoras, abastecidas com programas de rádio que orientam os pais a acompanhar a vida escolar de seus filhos.

\section{Os produtos de} comunicação dessas redes são dirigidos

a trabalhadores rurais, urbanos, comunicadores populares e camadas da população em situações de risco assistidas

por organizações não governamentais e entidades sociais ou governamentais na área das políticas públicas.

Seus conteúdos são de concepção informativo-formativa, abordam temas ligados à saúde, educação, ao meio-ambiente, desenvolvimento local, direitos (especialmente os das crianças), música e cidadania e embutem o compromisso permanente de transformar informação em compreensão.

Grande parte deste público também é formador de opinião. Está molecularmente distribuído pelas periferias e comunidades dos grandes centros urbanos e em pequenas e médias cidades do interior do País. São dirigentes sindicais rurais que atuam como comunicadores em seus programas de rádio; agentes sociais dos movimentos populares que se utilizam de rádios comunitárias, boletins e jornais institucionais para organizar a ação coletiva de seus representados e também de comunicadores de prestígio de pequenas e médias emissoras locais. 


\section{DESAFIOS}

Um grande desafio operacional enfrentado no trabalho com essas rádios parceiras é como garantir, num país tão grande e diverso como o Brasil, uma linguagem que respeite as diferenças regionais e que seja popular e compreensível para a maioria das pessoas. Outro grande desafio é como gerenciar o relacionamento com cada uma das emissoras, de forma a também respeitar as suas características técnicas, administrativas, de programação e de suas equipes - muito diversificadas tal qual o retrato do Brasil. Ainda outro desafio é como avaliar o resultado concreto do modelo de parceria e cooperação mantido com cada uma das rádios.

O relacionamento com o rádio defendido pela Oboré não é mediado pela compra de espaço nem pelo envio de releases; é o de tratá-lo como um aliado, verdadeiro parceiro estratégico na viabilização de produtos, processos e projetos radiofônicos. Não se refere, portanto, a uma operação comercial e sim a uma ação parceira e cooperante: convocar e estimular o viés cidadão e o compromisso que toda emissora deve ter na divulgação de assuntos de interesse público, inclusive por ser o rádio uma concessão pública.

Este modelo de relacionamento é materializado no Termo de Parceria e Cooperação-documento assinado entre emissora e produtora, estabelecendo a adesão voluntária da rádio a uma das redes da Oboré. Com isso, o comunicador responsável passa a receber, periódica e gratuitamente, programas e elementos de produção finalizados e prontos para irem ao ar, com espaço para conquista de patrocínio local.
Este método procura resolver três grandes necessidades sensíveis e demonstráveis, hoje, nas pequenas e médias emissoras do Interior do Brasil: falta de equipe para produções locais, falta de material de qualidade na programação e escassez de verbas de anunciantes.

Os princípios da parceria e cooperação preconizados no modelo de gestão das redes temáticas defendem que o material distribuído ao parceiro não pode ser um tapa-buraco de programação; deve, sim, ter qualidade técnica, pertinência social, gerar repercussão e discussão junto aos ouvintes, possibilitar novas idéias de programação, novas pautas. Deve também ajudar a capacitar os radialistas no trato de assuntos de interesse da população e ainda mais: ajudar as emissoras na busca de anúncios locais e, com isso, prover sua sustentabilidade.

Trata-se de administrar uma ação sistêmica e complexa, em que emissoras, patrocinadores e gestor são células de uma mesma estrutura, mutante e mutável, por natureza e por definição. Os patrocinadores alimentam o sistema através do apoio financeiro, colhendo os frutos em reforço de imagem ou venda real dos produtos anunciados. As rádios garantem a disseminação da informação, de forma regular. E a Oboré, enquanto administradora e gestora, retroalimenta todo o processo, garantindo a interatividade e a continuidade do projeto. 
Trata-se, realmente, de uma parceria e de uma cooperação o tempo todo. Nisso é que acreditamos e apostamos para projetos de comunicação em rádio, privilegiando o popular, privilegiando a possibilidade de alterar, privilegiando a linguagem oral, que é a característica principal do nosso povo, da nossa gente.

A prática tem demonstrado que o atual método de gerenciamento até agora aplicado às redes temáticas de rádio é viável e já trouxe resultados muito positivos. O crescimento constante e progressivo do número de adesões a essas redes denota, inclusive, que a parceria com as emissoras extrapola o acordo registrado no Termo de Parceria e Cooperação. Vale também destacar o importante papel que a Universidade pôde desempenhar na legitimação deste projeto, referendando que teoria, reflexão e prática podem e devem andar juntas, também de forma parceira e cooperante.
Resumo: A autora relata como foi organizada a gestão da comunicação na Oboré Projetos Especiais, um núcleo de criação, produção e distribuição de programas especiais para rádios cidadãs - comerciais e comunitárias. $\mathrm{O}$ artigo reflete como se deu a relaçāo entre a jornalista e os demais integrantes do núcleo, o qual abriga uma equipe heterogênea de profissionais das mais diversas áreas como engenheiros, editores, jornalistas, entre outros, buscando criar as condições necessárias para alinhar as ações do núcleo. No caso da Oboré, a autora mostra que o gestor deve atuar no momento gerencial da empresa e na mediação entre as diversas equipes e etapas do processo, valorizando a atividade intelectual e a prática reflexiva em cada ponto do sistema. A autora ressalta, ainda, a importância de se administrar uma ação sistêmica e comple$\mathrm{xa}$, onde emissoras, patrocinadores e gestor são células de uma mesma estruturâ, mutante e mutável, por natureza e por definição.

Palavras-chave: rádios comunitárias, redes temáticas, gestão da comunicação, Oboré

\section{Mending loose ends}

Abstract: The author reports on how communication management was organized at Oboré Projetos Especiais, a creation, production and distribution center for special programs for citizen radio stations - both commercial and community. The article reflects on how the relationship between the journalist and the remaining team members - a heterogeneous group of professionals with the most diverse backgrounds such as engineers, editors, journalists, among others - aims at creating the necessary conditions to put the center's actions in line with each other. In Oboré's case, the author shows that the manager must perform in the company's managerial stage and in the mediation among the several process teams and stages, valuing intellectual activities and reflexive practices in each point of the system. The author also stresses the importance of administering a systemic and complex action, through which broadcasters, sponsors and the manager are cells of a same structure, one that is mutant and mutable by nature and definition.

Key words: community radios, thematic networks, communication management, Oboré 